${ }^{2}$ Sherwin, Keith, and Horsley, Michael, Thermofluids, Chapman and Hall, New York, 1964, p. 646.

${ }^{3}$ Jeans, Sir James, Kinetic Theory of Gases, Cambridge Univ. Press, Cambridge, England, U.K., 1946.

${ }^{4}$ Barlow, Jewel, B., Ray, William, H., Jr., and Pope, Alex, Low Speed Wind Tunnel Testing, 3rd ed., Wiley, New York, 1999, p. 222.

${ }^{5}$ Stever, H. Guyford, "Condensation High Speed Flows," Section F, Fundamentals of Gas Dynamics, Vol. 3, edited by H. W. Emmons, Princeton Univ. Press, NJ, 1967, pp. 528-572.

${ }^{6}$ Shapiro, Asher, The Dynamics and Thermodynamics of Compressible Fluid Flow, Wiley, New York, 1953, pp. 94, 95.

R. P. Lucht Associate Editor

\section{Full-Field Experimental Investigations on Resonant Vibration of Cracked Rectangular Cantilever Plates}

\author{
Chien-Ching $\mathrm{Ma}^{*}$ and Dong-Ming Hsieh ${ }^{\dagger}$ \\ National Taiwan University, \\ Taipei 10617, Taiwan, Republic of China
}

\section{Introduction}

$\mathbf{E}$ LECTRONIC speckle pattern interferometry (ESPI) was proposed in the $1970 \mathrm{~s}^{1}$ as a method of producing interferograms without using a traditional holographic technique. ${ }^{2}$ The main difference between ESPI and holography is the interferometric image processing. The image data are digitized by a video camera and digital signal processor for the ESPI method, which eliminates timeconsuming chemical development. Because the interferometric image is recorded and updated by the video camera every $\frac{1}{30}$ s, ESPI is faster in operation and more insensitive to environmental noise than holography. The comparative advantage of operation allows ESPI to extend its application compared with other optical measurement techniques. To increase the visibility of the fringe pattern and to reduce the environmental noise simultaneously, an amplitudefluctuation ESPI method was proposed by Wang et al. ${ }^{3}$ for outof-plane vibration measurement. In the amplitude-fluctuation (AF) ESPI method, the reference frame is recorded in a vibrating state and subtracted from the incoming frame. Ma and Huang ${ }^{4}$ and Huang and $\mathrm{Ma}^{5}$ used the AF-ESPI method to investigate the three-dimensional vibrations of piezoelectric rectangular parallelepipeds and cylinders; both the resonant frequencies and the mode shapes were presented and discussed in detail.

The study of the vibration behavior of plates with a crack is a problem of great practical interest. Only a few papers have been published on the vibration analysis of a finite cracked plate. This problem combines the fields of vibration analysis and fracture mechanics. If the cracked plate is in resonance, the crack can propagate either explosively or faster than in the early stage. To avoid the mentioned fracture produced by vibration, it is necessary that the vibration characteristics of the cracked cantilever plate be clarified. Nevertheless, compared with studies in the past, there is little research on the influence of cracks on the vibration behavior of plates.

In this Note, we employ an optical method based on the AF-ESPI to study the resonant properties of rectangularcantilever plates with

Received 18 July 2000; revision received 20 April 2001; accepted for publication 4 June 2001. Copyright (C) 2001 by the American Institute of Aeronautics and Astronautics, Inc. All rights reserved. Copies of this paper may be made for personal or internal use, on condition that the copier pay the $\$ 10.00$ per-copy fee to the Copyright Clearance Center, Inc., 222 Rosewood Drive, Danvers, MA 01923; include the code 0001-1452/01 \$10.00 in correspondence with the CCC.

*Professor, Department of Mechanical Engineering; cma@w3.me.ntu. edu.tw.

Graduate Student, Department of Mechanical Engineering. cracks. The rectangular cantilever plate is clamped along one edge and free along the other three edges; a straight crack is located along the clamped edge. The advantage of using the AF-ESPI method is that resonant frequencies and the corresponding mode shapes can be obtained simultaneously from the experimental measurement. In addition to the AF-ESPI method, numerical computations based on a finite element package are presented, and good agreement is found in comparison with experimental results for both the resonant frequency and vibration mode shapes. The quantitative magnitudes of the full field vibration displacements are also indicated in the experimental results, which are in the order of a micrometer.

\section{Experimental Measurements and Numerical Results}

The optical arrangement for out-of-plane vibrating measurement by ESPI is shown schematically in Fig. 1. If the image is taken after the specimen vibrates periodically, the light intensity detected by a charge-coupled device (CCD) camera is indicated as $I_{1}$. The AFESPI method is employed in this study by taking two images while the specimen vibrates and assuming that the vibration amplitude of the second image has changed from $A$ to $A+\Delta A$ due to the unstability of apparatus. The light intensity of the second image is indicated as $I_{2}$. When these two images $\left(I_{1}\right.$ and $\left.I_{2}\right)$ are subtracted and rectified by the image processing system, the resulting image intensity can be expressed as ${ }^{4}$

$$
I=I_{2}-I_{1}=\sqrt{I_{A} I_{B}} / 2\left|(\cos \phi) \Gamma^{2}(\Delta A)^{2} J_{0}(\Gamma A)\right|
$$

where $I_{A}$ is the object light intensity, $I_{B}$ is the reference light intensity, $\phi$ is the phase difference between object and reference light, $J_{0}$

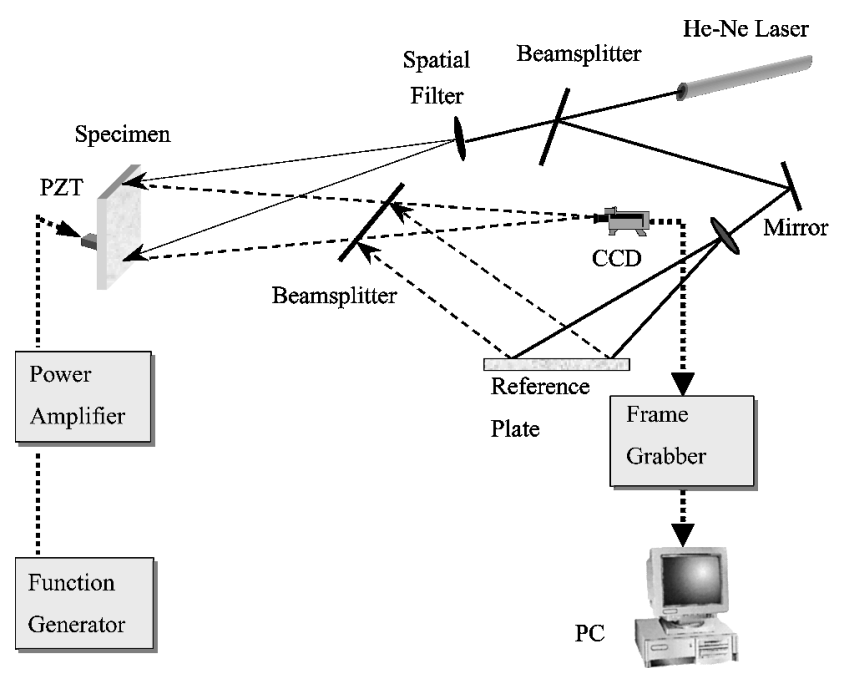

Fig. 1 Schematic diagram of ESPI experimental setup for out-of-plane measurement.

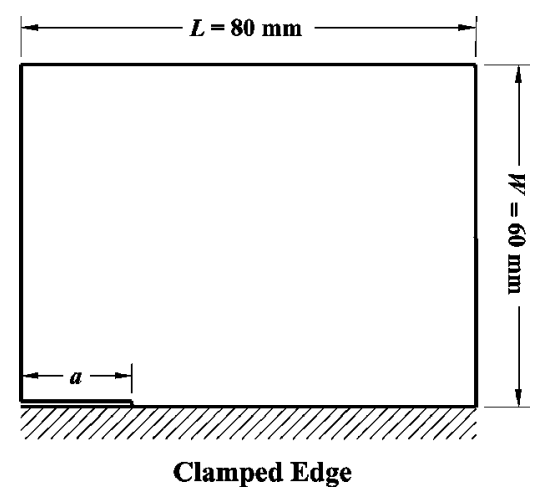

Fig. 2 Geometric dimensions and configuration of cracked rectangular plates: thickness $h=1 \mathrm{~mm}$ and crack length $a=20,35$, and $50 \mathrm{~mm}$. 
is a zero-order Bessel function of the first kind, and

$$
\Gamma=2 \pi(1+\cos \theta) / \lambda
$$

in which $\lambda$ is the wavelength of laser and $\theta$ is the angle between object light and observation direction.

Three cracked rectangular aluminum plates (6061T6) with different crack length $(20,35$, and $50 \mathrm{~mm})$ are used in this study for vibration analysis. The rectangularcantileverplate is clamped along one edge and free along the other three edges; a straight crack is located along the clamped edge. The material properties of the plate are mass density $\rho=2700 \mathrm{~kg} / \mathrm{m}^{3}$, Young's modulus $E=70.9 \mathrm{GPa}$ and Poisson's ratio $v=0.33$. The location of crack and the geometric dimension of the cracked rectangular plate is shown in Fig. 2.

A He-Ne laser with $30-\mathrm{mW}$ and wavelength $\lambda=632.8 \mathrm{~nm}$ is used as the coherent light source. The laser beam is divided into two parts, the reference beam and object beam, by a beamsplitter. The object beam travels to the specimen and then reflects to the CCD camera (Pulnix Company). The reference beam goes directly to the CCD camera via a mirror and a reference plate. The CCD camera convert the intensity distribution of the interferencepattern of the objectinto a corresponding video signal at $30 \mathrm{frames} / \mathrm{s}$. The signal is electronically processed and converted into an image on the video monitor. The interpretation of the fringe image is similar to reading a contour map of the displacement field. The plate is excited to resonance by a piezostack actuator (PI Company, $2 \times 3 \times 20 \mathrm{~mm}$ ) that is attached behind the specimen. To achieve the sinusoidal output, a digitally controlled function generator HP33120A (Hewlett-Packard Company) connected to a 4005 power amplifier (NF Corporation) is used.

Numerical results of resonant frequencies and mode shapes are obtained by using the ABAQUS finite element package. ${ }^{6}$ A total number of 1200 elements with eight-node two-dimensional shell elements (S8R5) are used in the analysis. This element approximates the Midlin-type element that acounts for rotary inertia effects and first-order shear deformations through the thickness.

Table 1 shows the experimental and numerical results of the first 10 resonant frequencies for cracked cantilever plates with different crack lengths $(20,35$, and $50 \mathrm{~mm})$. The results are quite consistent. Note that all of the experimental measured frequencies are lower than the numerical ones. The main reason is believed to be that the clamped condition of the cracked cantilever plate for the experimental setup is not ideally rigid. Furthermore, the errors for measuring the material properties and the thickness of the plate may also influence the calculated results for resonant frequencies.

The contours of the resonant mode shapes obtained from the finite element calculation are plotted for comparison with the experimental ones. Figures 3-5 show the first 10 mode shapes of cracked cantilever plates for both experimental measurements and

Table 1 Results of first 10 resonant frequencies obtained from AF-ESPI and finite element method for different crack lengths

\begin{tabular}{|c|c|c|c|c|c|c|c|c|c|c|c|}
\hline \multirow{2}{*}{$\begin{array}{l}\text { Crack } \\
\text { length, } \mathrm{mm}\end{array}$} & \multirow[b]{2}{*}{ Method } & \multicolumn{10}{|c|}{ Frequency $(\mathrm{Hz})$ for mode number: } \\
\hline & & 1 & 2 & 3 & 4 & 5 & 6 & 7 & 8 & 9 & 10 \\
\hline \multirow[t]{2}{*}{20} & AF-ESPI & 196 & 397 & 964 & 1244 & 1454 & 2154 & 2544 & 2988 & 3969 & 4224 \\
\hline & $\mathrm{FE}^{\mathrm{a}}$ & 224 & 418 & 1012 & 1393 & 1652 & 2329 & 2634 & 3133 & 4227 & 4508 \\
\hline \multirow[t]{2}{*}{35} & AF-ESPI & 167 & 322 & 711 & 1140 & 1355 & 1912 & 2444 & 2758 & 3618 & 4050 \\
\hline & FE & 188 & 344 & 754 & 1220 & 1558 & 2025 & 2564 & 2852 & 3842 & 4278 \\
\hline \multirow[t]{2}{*}{50} & AF-ESPI & 124 & 244 & 582 & 1039 & 1287 & 1841 & 2084 & 2577 & 3170 & 3809 \\
\hline & FE & 140 & 268 & 618 & 1106 & 1493 & 1918 & 2163 & 2661 & 3334 & 4143 \\
\hline
\end{tabular}

${ }^{\mathrm{a}}$ Finite element.

Mode 1

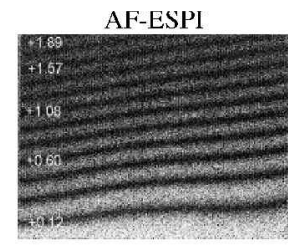

Mode 2

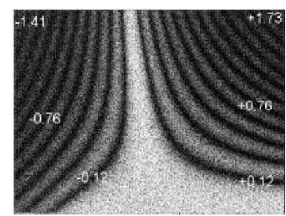

Mode 3

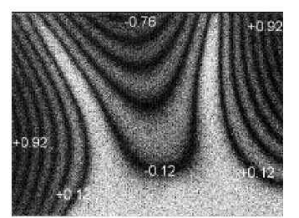

Mode 4

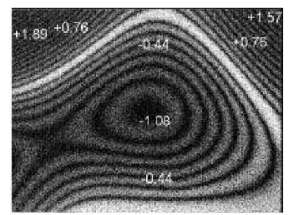

Mode 5

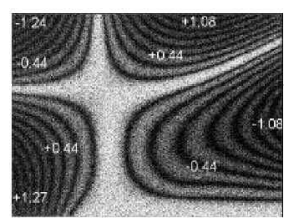

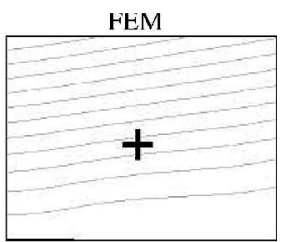
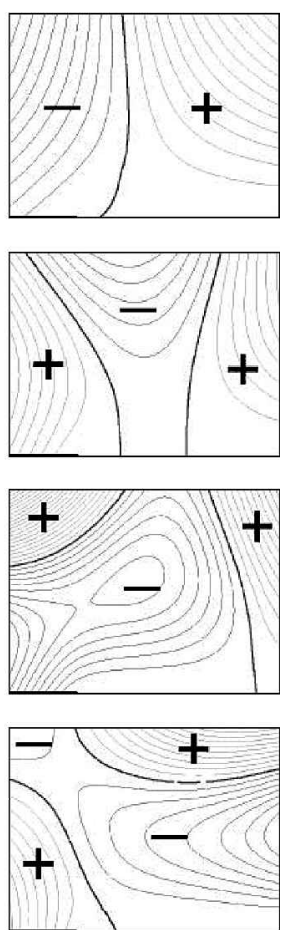

Mode 6
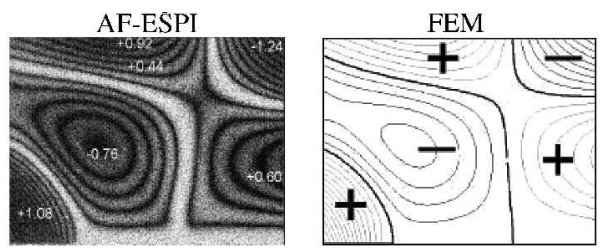

Mode 7
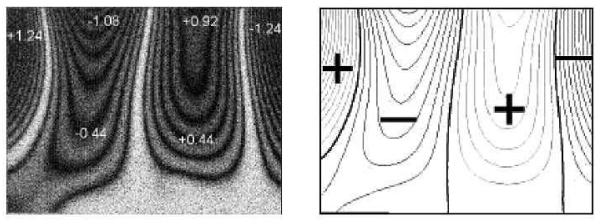

Mode 8
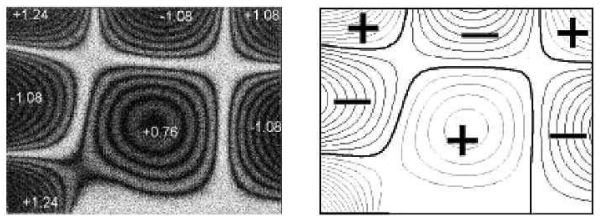

Mode 9
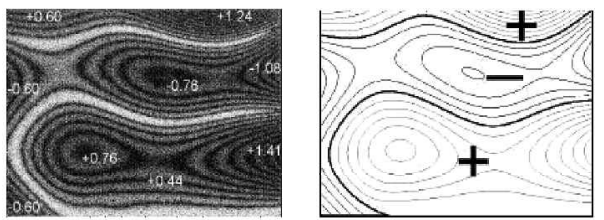

Mode 10
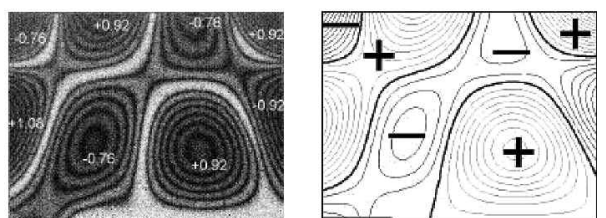

Fig. 3 First 10 mode shapes of the cracked rectangular plate with $a=20 \mathbf{~ m m}$ obtained by AF-ESPI and finite element method (FEM). 

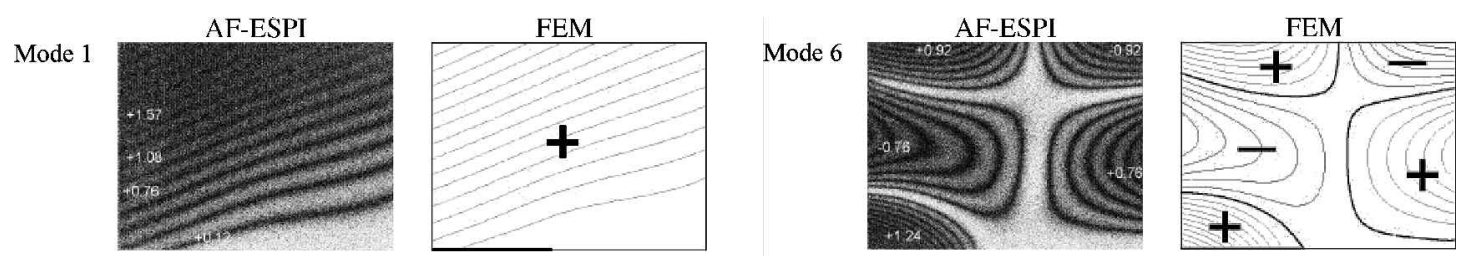

Mode 2
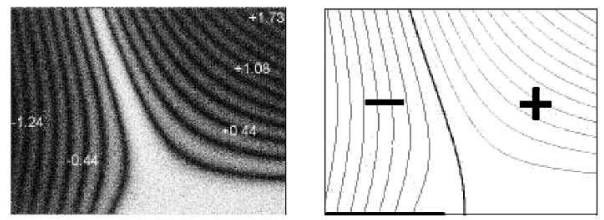

Mode 7
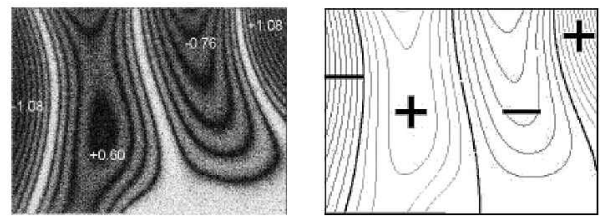

Mode 3
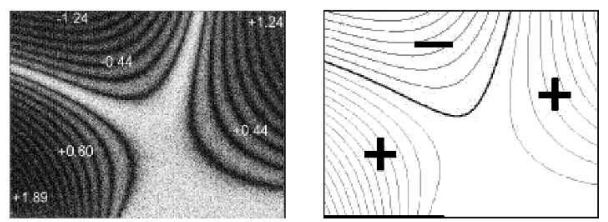

Mode 8
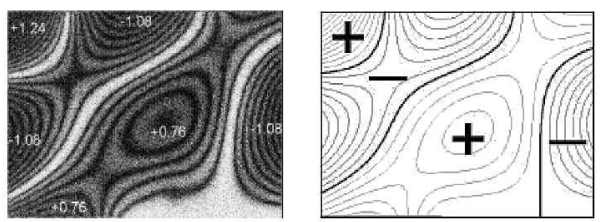

Mode 4
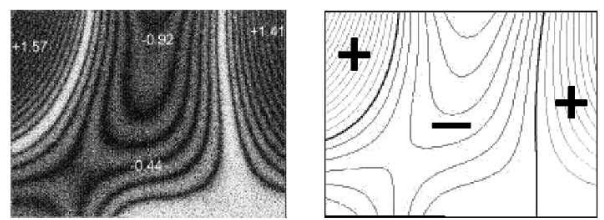

Mode 5
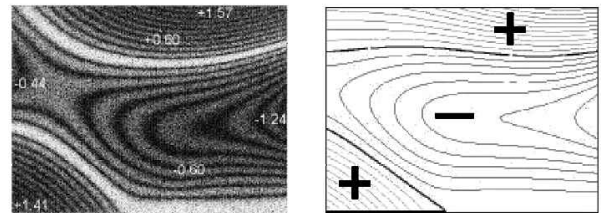

Mode 9
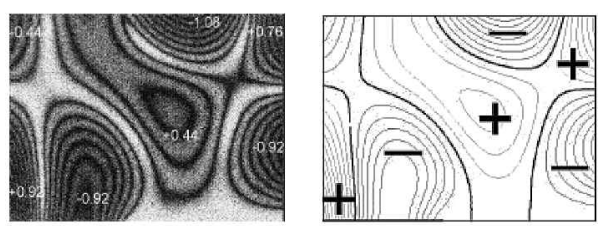

Mode 10
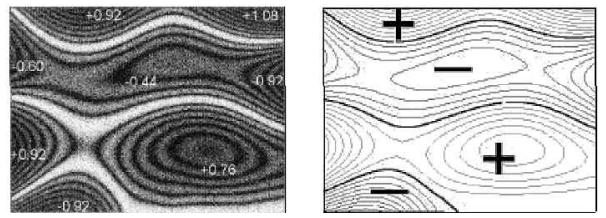

Fig. 4 First 10 mode shapes of the cracked rectangular plate with $a=30 \mathrm{~mm}$ obtained by AF-ESPI and FEM.
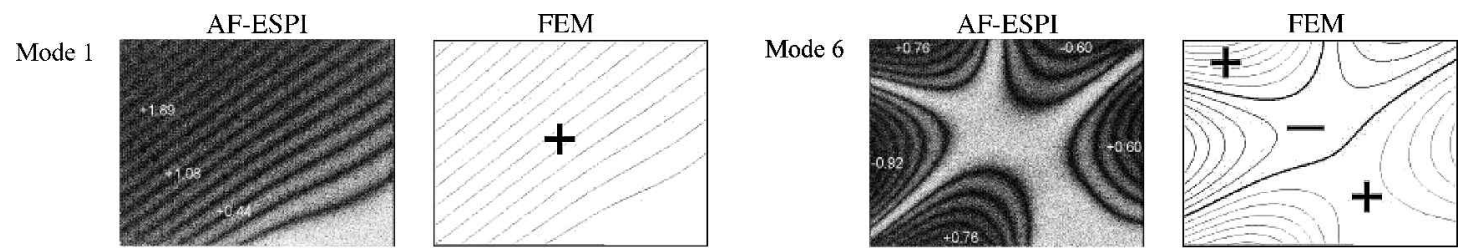

Mode 2
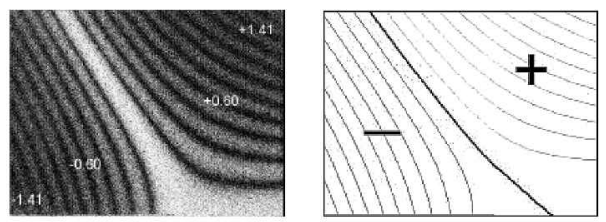

Mode 7
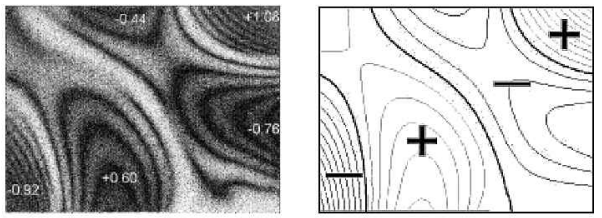

Mode 3
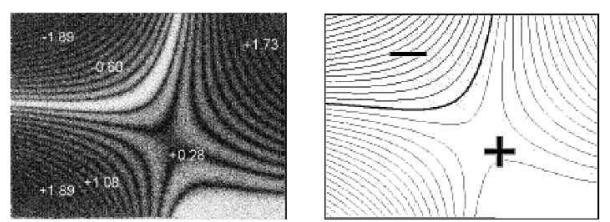

Mode 8
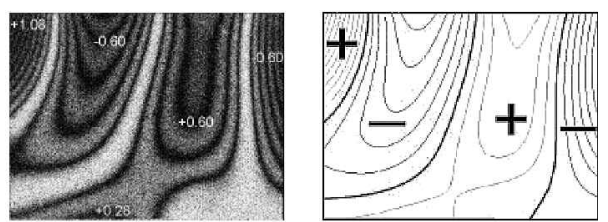

Mode 4
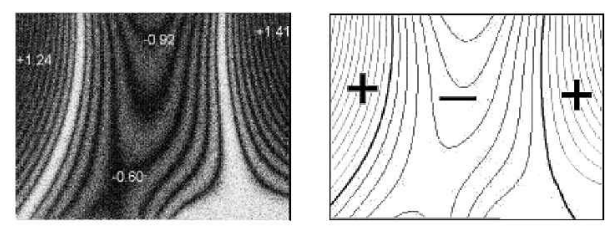

Mode 5
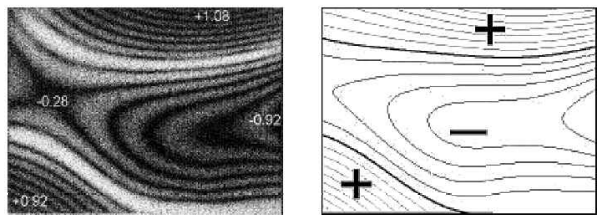

Mode 9
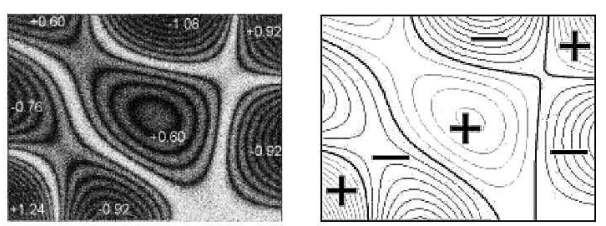

Mode 10
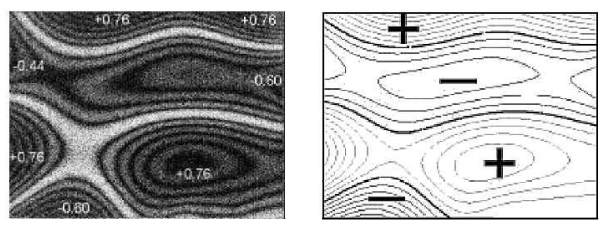

Fig. 5 First 10 mode shapes of the cracked rectangular plate with $a=50 \mathrm{~mm}$ obtained by AF-ESPI and FEM. 
numerical simulations. The excellent quality of the interferometric fringe patterns obtained from the AF-ESPI method is demonstrated. In Figs. 3-5, we indicate the phase of displacement in finite element results with $\mathrm{a}+$ or - sign. The regions of the same sign have inphase motion, and nodal lines (thick black lines) are also shown in Figs. 3-5. The brightest fringes on the experimentalresults represent the nodal lines of the vibrating cracked plate at resonant frequencies. The rest of the fringes are contours of constant displacement. It can be seen that the vibration mode shapes obtained experimentally agree very well with those obtained from the finite element method.

The related amplitude $A_{i}, i=1,2,3, \ldots, n$, for the $i$ th fringe in the experimental results can be quantitatively calculated by the roots $R_{i}$ of $J_{0}\left(\Gamma A_{i}\right)=0$. The first 10 roots $R_{i}$ for $J_{0}\left(R_{i}\right)=0$ are 2.4 , $5.52,8.65,11.79,14.93,18.07,21.21,24.35,27.49$, and 30.63. The correspondent amplitude $A_{i}$ of the out-of-plane displacement can be evaluated by the following equation:

$$
A_{i}=\frac{\lambda R_{i}}{2 \pi(1+\cos \theta)}
$$

We use $\theta=10 \mathrm{deg}$ for the experimental setup and $\lambda=632.8 \mathrm{~nm}$; the related amplitudes for the first 10 dark fringes are $A_{i}, i=$ $1 \sim 10,=0.12,0.28,0.44,0.6,0.76,0.92,1.08,1.24,1.41$, and $1.57 \mu \mathrm{m}$. The maximum value of the vibration displacement and related amplitudes of some fringes in the experimental results are indicated in Figs. 3-5. Note that the vibration displacements obtained in this study are in the order of a micrometer.

Because the crack will introduce a new free boundary of the cantilever plate, the mode shape of a cracked plate is complicated and quite different from that of a plate without a crack. A complete discussion of out-of-plane vibration mode shapes for different boundary conditions of isotropic plates without cracks was presented by Huang and Ma. ${ }^{7}$ The vibrating mode shapes of the first and the second modes shown in Figs. 3-5 are pure bending and torsion modes, respectively. The mode shapes for long cracks (Figs. 4 and 5; $a=35$ and $50 \mathrm{~mm}$ ) are similar, but they are quite different if compared with mode shapes for the short crack (Fig. 3; $a=20 \mathrm{~mm}$ ). Note that the displacements along the crack surface for the first 10 modes are all in-phase for the short crack and that the nodal lines will not pass the crack surface. However, the nodal lines of modes 7 and 9 for long cracks are terminated at the crack surface.

\section{Conclusions}

Investigation of the vibration problem by employing the ESPI method has the advantages of real-time and noncontact measurement, submicron sensitivity, digital image processing, and so on. In this Note, a self-arranged AF-ESPI optical setup with good fringe visibility and noise reduction was established to obtain the resonant frequencies and corresponding mode shapes of cantilever cracked plates at the same time. Compared with the spectrum analysis method or modal analysis method, AF-ESPI is more convenient in experimental measurement, and excellent quality of the interferometric fringe patterns are obtained. Numerical calculations of resonant frequencies and mode shapes based on a finite element package are also performed, and good agreement is obtained in comparison with experimental measurements. The influence of the crack length on the vibration behavior of the cantilevercracked plate is discussed in detail. Note that frequencies obtained experimentally are typically lower than theoretical ones because one cannot get the perfectly rigid clamping condition.

\section{Acknowledgment}

The authors thank the National Science Council (NSC) of the Republic of China for supporting this research under Grant NSC 87-2218-E002-022.

\section{References}

${ }^{1}$ Rastogi, P. K., Holographic Interferometry, Springer-Verlag, Berlin, 1994

${ }^{2}$ Butters, J. N., and Leendertz, J. A., "Speckle Pattern and Holographic Techniques in Engineering Metrology," Optics Laser Technology, Vol. 3, No. 1,1971 , pp. 26-30
${ }^{3}$ Wang, W. C., Hwang, C. H., and Lin, S. Y., "Vibration Measurement by the Time-Averaged Electronic Speckle Pattern Interferometry Methods," Applied Optics, Vol. 35, No. 22, 1996, pp. 4502-4509.

${ }^{4}$ Ma, C. C., and Huang, C. H., "The Investigation of Three-Dimensional Vibration for Piezoelectric Rectangular Parallelepipeds Using the AF-ESPI Method,' IEEE Transactions on Ultrasonics, Ferroelectrics, and Frequency Control, Vol. 48, No. 1, 2001, pp. 142-153.

${ }^{5}$ Huang, C. H., and Ma, C. C., "Vibration Characteristics for Piezoelectric Cylinders Using Amplitude-Fluctuation Electronic Speckle Pattern Interferometry," AIAA Journal, Vol. 36, No. 12, 1998, pp. 2262-2268.

6“ABAQUS User's Manual," Ver. 5.5, Hibbit, Karlsson, and Sorensen, Inc., Pawtucket, RI, 1995.

${ }^{7}$ Huang, C. H., and Ma, C. C., "Experimental Measurement of Mode Shapes and Frequencies for Vibration of Plates by Optical Interferometry Method,'Journal of Vibration and Acoustics, Vol. 123, No. 2, 2001, pp. 276280

A. M. Waas Associate Editor

\section{Static and Dynamic Validations of a Refined Thin-Walled Composite Beam Model}

\author{
Zhanming Qin* and Liviu Librescu ${ }^{\dagger}$ \\ Virginia Polytechnic Institute and State University, \\ Blacksburg, Virginia 24061-0219
}

\section{Introduction}

$\mathbf{T}$ HE increasing need for weight saving and structural efficiency of aerospace vehicles has prompted wide use of thin-walled beam structures. ${ }^{1}$ At the same time, due to the increased importance of composite materials in the design of aerospace vehicles, the concept of anisotropic thin-walled beam model has reached special prominence in the last two decades. ${ }^{1,2}$ However, in contrast to the metallic structures, the composite structures exhibit significant nonclassicaleffects such as transverse shear, warping restraint, three-dimensionalstrain effect, and contourwise shear stiffness variations. Toward a reliable design, these effects should be accounted for and assessed even in the predesign process. In fact, in the past years, a number of analytical models of anisotropic thin-walled beams have been proposed and validated either numerically or in light of the experimental evidence. ${ }^{2}$ On the other hand, although a refined thin-walled beam theory originally developed by Song ${ }^{3}$ and Librescu and Song ${ }^{1}$ has been extensively used for the study, among others, of dynamic response/structural feedback control ${ }^{3-10}$ and static aeroelasticity, $3,71,12$ no validations of it against the experimental, analytical, or numerical predictions obtained within other thin-walled beam models are available in literature. Within the frame of this refined model, some effects such as the three-dimensional strain effect ${ }^{13,14}$ and nonuniformity effect of contourwise shear stiffness, that are also usually significant for the laminated composite beams $s^{2,13-15}$ and were not formerly accounted for, are further incorporated, and the model hereby developed is investigated against the available data from experiments, finite element method, and other analytical models.

\section{Theory}

A single-cell, closed cross section, fiber-reinforced composite thin-walled beam is considered. The coordinate system that is

Received 3 January 2001; revision received 20 August 2001; accepted for publication 21 August 2001. Copyright (C) 2001 by the American Institute of Aeronautics and Astronautics, Inc. All rights reserved. Copies of this paper may be made for personal or internal use, on condition that the copier pay the $\$ 10.00$ per-copy fee to the Copyright Clearance Center, Inc., 222 Rosewood Drive, Danvers, MA 01923; include the code 0001-1452/01 \$10.00 in correspondence with the CCC.

* Graduate Teaching Assistant, Department of Engineering Science and Mechanics. Student Member AIAA.

${ }^{\dagger}$ Professor, Department of Engineering Science and Mechanics. 